\title{
First record of Acropora gemmifera in the main Hawaiian Islands
}

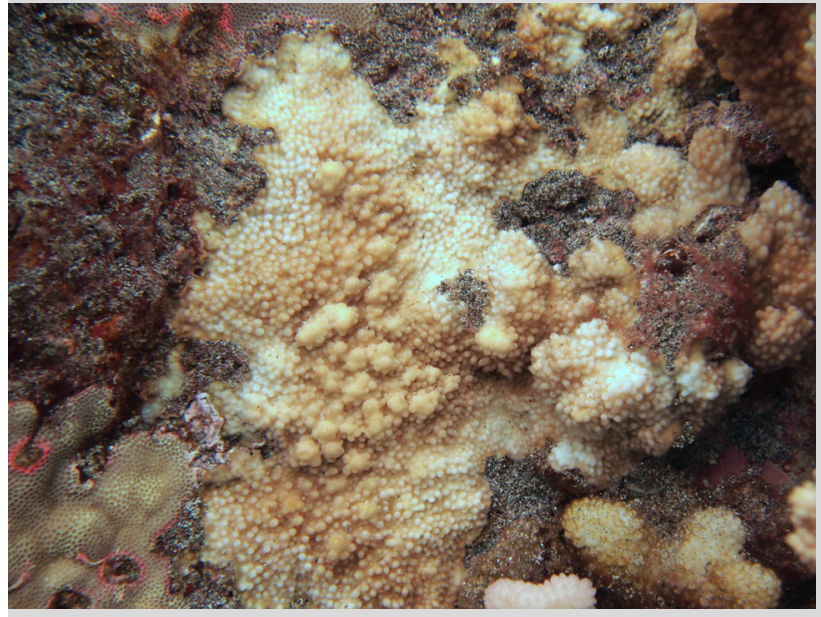

Fig. 1 Acropora gemmifera encrusting form

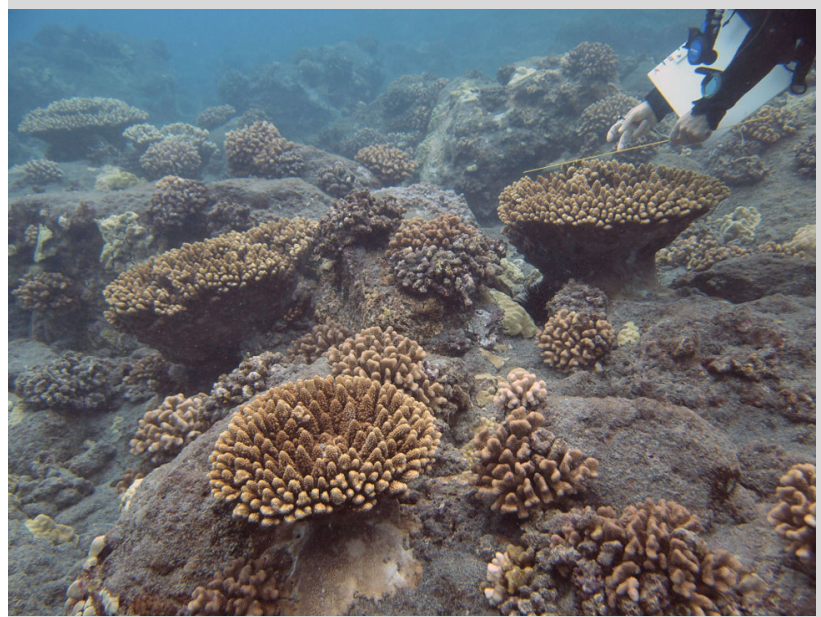

Fig. 2 Multiple colonies of Acropora gemmifera

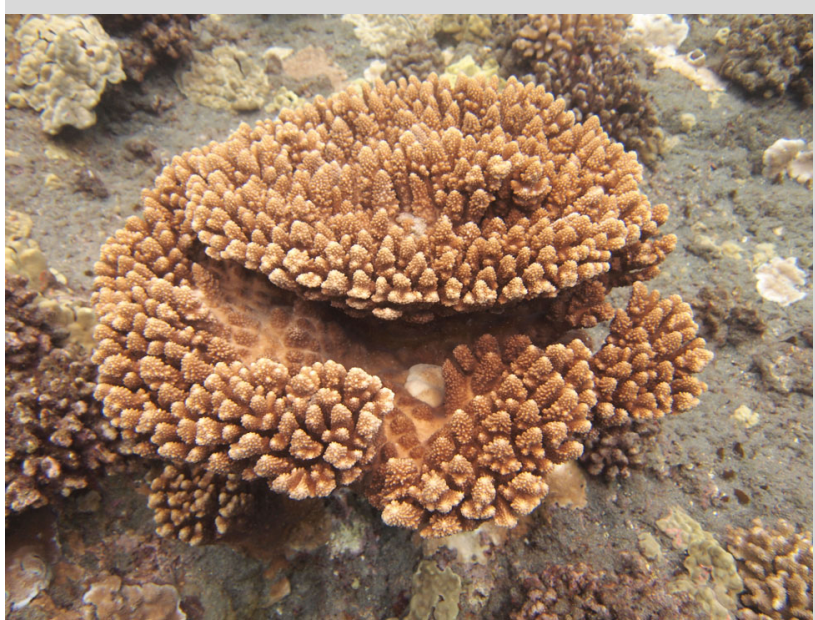

Fig. 3 Large colony of Acropora gemmifera with white tumor (growth anomaly) just below center of image
Seven species of Acropora stony corals have been recorded in the Hawaiian Archipelago. All species but the table coral Acropora cytherea are currently restricted to the central Northwestern Hawaiian Islands, from Necker Island to Pearl and Hermes Atoll (Asher et al. 2012). In the Main Hawaiian Islands, several small colonies of $A$. cytherea have been reported from Kaua ' $i$ and a single large colony $(100 \times 60 \mathrm{~cm})$ was recently sighted off $\mathrm{O}$ ‘ahu (Kosaki et al. 2013). There have been no historical reports of any Acropora species occurring around the Island of Hawai' $i$, the southernmost island in the archipelago, nor were any observed in over 4,300 coral reef monitoring/research dives over the past 14 years.

In April 2013 during the course of a reconnaissance dive utilizing diver propulsion vehicles, we came across a large number of Acropora gemmifera colonies in South Kona on the West Coast of the Island of Hawai 'i. Visual identification was subsequently confirmed by Narrissa Spies (personal communication) based on sequencing of the Pax-C 46/47 nuclear intron.

A total of $75 \mathrm{~A}$. gemmifera colonies occurred in an approximately 50-m stretch of reef in depths ranging from 3 to $9.8 \mathrm{~m}$ $($ mean $=5.9 \mathrm{~m}$, median $=5.8 \mathrm{~m})$. Colonies ranged in size from small encrusting forms (Fig. 1) to large upright digitate colonies (Fig. 2), the largest of which (Fig. 3) was $71 \times 68 \times 75.5 \mathrm{~cm}$ (LWH). Based on linear growth rates for a morphologically similar species, Acropora humilis, in the Red Sea (Attalla et al. 2011), we can speculate that $A$. gemmifera has been present in this area for at least 80 years.

Acknowledgments The authors give special thanks to Narrissa P. Spies of the Richmond Lab, Kewalo Marine Laboratory, Pacific Biomedical Research Center, Honolulu. This work was supported by the NOAA Coral Reef Conservation Program Main Hawaiian Islands Assessment and Monitoring Program.

\section{References}

Asher J, Maragos J, Kenyon J, Vargas-Ángel B, Coccagna E (2012) Range extensions for several species of Acropora in the Hawaiian Archipelago and the Papahānaumokuākea Marine National monument. Bull Mar Sci 88:337-338

Attalla TM, Hanafy MH, Aamer MA (2011) Growth rates of the two reefbuilding species, Acropora humilis and Millepora platyphylla at Hurghada, Red Sea, Egypt. Egypt J Aquat Biol Fish 15:1-15

Kosaki RK, Wagner D, Leonard JC, Hauk BB, Gleason KA (2013) First report of the Table Coral Acropora cytherea (Scleractinia: Acroporidae) from Oahu (Main Hawaiian Islands). Bull Mar Sci 89:745-746

W. J. Walsh $(\bowtie) \cdot$ S. Cotton · L. Jackson · M. Lamson

R. Martin · K. Osada-D'Avella · L. Preskitt

Hawai 'i Division of Aquatic Resources, Kailua-Kona, HI 96740, USA

e-mail: darkona@hawaiiantel.net

Received: 19 July 2013/Accepted: 14 October 2013/Published online: 27 October 2013

Coral Reefs (2014) 33:57

(C) Springer-Verlag Berlin Heidelberg 2013

DOI $10.1007 / \mathrm{s} 00338-013-1092-3$ 